\title{
NUEVA INTERPRETACIÓN DEL PASADO EN LOS RELATOS HISTÓRICOS DE BERYL BAINBRIDGE
}

\section{M..$^{a}$ Antonia Álvarez Calleja}

Universidad Nacional de Educación a Distancia

Beryl Bainbridge comenzó como escritora de novelas policíacas macabras, logrando su literatura el mayor esplendor en ese área resbaladiza y dudosa que media entre la tragedia y la farsa. Pero recientemente, como afirma Barbara C. Millard (1982: 40), sus obras han recibido una atención crítica seria por el estilo económico y elegante de sus retratos intrigantes, y al mismo tiempo cómicos, de gentes de la clase media baja, acosadas y atrapadas en un mundo amenazador y cargado de temores. Esos originales relatos necesitan, al menos, una segunda lectura para poder comprender todas las sugerencias de un lenguaje cargado de significados.

En la ficción de Beryl Bainbridge destaca principalmente la brusquedad psicológica y los actos de violencia extrema de sus personajes, aparentemente vulgares, pertenecientes a la clase trabajadora. Gran parte de su comedia negra, casi macabra, se basa en recuerdos y reflexiones de su adolescencia en Liverpool, bajo la aterradora amenaza de la segunda Gue- 
rra Mundial. Aunque en una entrevista concedida a Brad Crawford (1999: 8) Bainbridge confiese que no se considera una experta en novela histórica, en los relatos en que se libera de su entorno y de su época inventa otras voces diferentes de la suya para los personajes que surgen del campo de su imaginación, pero siempre dedicando el tiempo necesario a la investigación de los episodios que interesan a la narración, ya que no puede lanzarse a escribir en un marco situacional donde sus personajes no se muevan con naturalidad.

\section{FICCIÓN HISTÓRICA VS. HISTORIA}

La literatura ha sido siempre una fuente útil para la Historia y los historiadores, y no sólo es reflejo de los hechos históricos, sino una forma de crear y recrear la Historia; por eso el término relato histórico, lejos de indicar un conjunto bien definido de convenciones, se aplica a una extensa variedad de materias y estrategias artísticas.

Muchos autores han escrito relatos que se consideran ficción histórica, en el sentido de que ocurren en períodos anteriores al nacimiento del escritor, ya que la Historia ha ofrecido un material virtualmente inagotable de incidentes, marcos y caracteres que han sido usados por escritores cuyo propósito principal era contar una buena historia, y si la Historia puede novelarse, también puede volver a imaginarse de otras formas, con relatos de historias alternativas que intentan comprender la historia del pasado.

Patrick Swinden (1984: 128) nos recuerda la superposición que se produce entre la ficción y la Historia como formas de narrativa, pues el significado y la función de la novela a través de los diferentes períodos siempre se relacionan, al menos en parte, con la forma en que estos períodos imaginan y narran su propia historia. Si aceptamos que las novelas son parte de la historia de la vida social, porque proporcionan pruebas de la manera en que otros han construido la Historia o las relaciones históricas, admitimos que las novelas son formas de hacer Historia; pertenecen a la historia de los hechos ocurridos y contribuyen a la narración histórica de esos acontecimientos.

El relato histórico puede describirse como una estructura en la que se combinan la ficción y los datos históricos verificables. La Historia y la ficción histórica tienen mucho en común porque, como afirman Cox y Adrian:

they are both imaginative constructs since all historical narrative is, to some extent, history re-made and re-fashioned, since the writing of history and historical fiction are complementary means of understanding the past (1994: ix). 
No obstante, aunque el relato histórico encuentre su propio camino siguiendo la vida interna del pasado, R.G. Collingwood considera que un método académico no debería seguirlo, aunque los dos traten de recobrar el pasado, porque:

\begin{abstract}
...each of them makes it his business to construct a picture which is partly a narrative of events, partly a description of situations, exhibition of motives, analysis of characters. Each aims at making his picture a coherent whole, where every character and every situation is so bound up with the rest that this character in this situation cannot but act in this way, and we cannot imagine him as acting otherwise. The novel and the history must both of them make sense; nothing is admissible in either except what is necessary, and the judge of this necessity is in both cases the imagination (1946: 245-6).
\end{abstract}

El novelista histórico es menos pretencioso que el historiador para Serge Heirbrant (1993: 19), porque presenta su punto de vista del pasado simplemente como ficción; pero, en realidad, abusa de su omnisciencia autorial para conseguir que su lector acepte como verdadero su concepto particular del pasado, donde normalmente se mezclan los hechos con la ficción, debiendo ser consciente del pacto que establece con sus lectores. Por ello, el lector que entra en el mundo del autor debe recibir una interpretación responsable de cómo eran realmente las cosas, ya que cuando se concede prioridad al pacto implícito entre lector-escritor, el período de historia novelado no sólo perdura como Historia, sino que, a través de la relación que se establece, puede también formar parte del presente. De ahí que los tres relatos de Beryl Bainbridge (Every Man for Himself, The Birthday Boys, Master Georgie) ofrezcan, según Elizabeth Wënno:

.... a historical or empirical mimetic «slice of life» for the reader to partake in, but the fashion of the presentation prevents the reader from doing this through its tantalizing narrative structure and ironic quality (1993: 66).

A estos tres relatos históricos de Bainbridge, y con la misma cualidad irónica que los caracteriza, quizás pueda añadirse otro, Young Adolf, ya que lo ha construido sobre una figura histórica: el joven Hitler.

\title{
Every Man for Himself
}

Hay ciertos temas en nuestra cultura que producen un flujo continuo de novelas y películas, y el hundimiento del Titanic es uno de ellos. Este desas- 
tre tuvo una serie de causas, pero quizás la principal fuera que casi la mitad de la capacidad de los botes salvavidas del Titanic no pudo usarse de forma adecuada, porque no había instrucciones para la correcta embarcación de los pasajeros en una situación de emergencia tan extrema.

Beryl Bainbridge no elige todos los personajes a bordo como reparto, sino que se concentra en un grupo que de diversas maneras está conectado con el narrador en primera persona, un joven conocido tan sólo como Morgan. El joven Morgan es el sobrino americano del dueño de la línea de transporte marítimo, quien, como aprendiz de dibujante, tuvo una parte muy pequeña en la construcción del Titanic. Los orígenes de Morgan son misteriosos; aparentemente es una especie de huérfano que había sido rescatado de la pobreza por un matrimonio fortuito de su tía con el millonario J. P. Morgan; rescatado, pero no enteramente liberado, ya que su formidable tío espera que encuentre algún tipo de empleo. Pero, a pesar de todo, a bordo tiene mucho tiempo y oportunidades para beber y meterse en líos.

En las últimas páginas, cuando el barco se está hundiendo, la orquesta toca canciones famosas, mientras los pasajeros corren confusos por todas partes. Algunos siguen sentados jugando a las cartas en la sala de fumadores, esperando tranquila y estoicamente el final, acompañados de un borracho cómico que de vez en cuando levanta la cabeza de la mesa y pide disculpas por «si es una conversación privada», $\mathrm{y}$ ofrece «marcharse de puntillas como un duende.»

En este relato Beryl Bainbridge - aunque el sentido de inmediatez y de presencia no sea tan fuerte como en The Birthday Boys, porque en esta plataforma flotante, densamente poblada, se siente menos la sensación de trágica soledad que en la llanura de hielo sobre la que los cinco hombres llevan a cabo su empuje final hacia el Polo Sur - cuenta este suceso memorable con una observación tan meticulosa, que asombra su exactitud con lo que posiblemente ocurrió en el trasatlántico condenado a sumergirse en las profundidades del océano.

\section{The Birthday Boys}

Este relato narra otro hecho memorable: la funesta expedición al Polo Sur dirigida por Robert Falcon Scott, basándose Bainbridge en los documentos históricos existentes, para conseguir que el lector experimente la misma sensación que si hubiera sido él quien avanzara por el paisaje helado azotado por la ventisca.

Scott estaba decidido a alcanzar el Polo antes que su rival, Roald Amundsen. En enero de 1912 él y su equipo llegaron al Polo, a pesar de una serie de 
desgraciados incidentes, pero los noruegos ya habían estado allí y se habían marchado un mes antes. En su viaje de vuelta, Scott y todo el grupo murió a causa del frío y el hambre. El fracaso de esta expedición fue debido a que careció del prosaico profesionalismo del equipo noruego que alcanzó el Polo sin víctimas. No obstante, esta incompetencia —según Daniel M. Murtaugh (1998: 192) - fue el motivo que ofreció un modelo de heroísmo para los jóvenes ingleses. Durante años, los hombres de Scott fueron ejemplo de valentía en Inglaterra, aunque ya más recientemente se considere que la terquedad de Scott y su falta de preparación no son aconsejables en una empresa de tal magnitud, ya que probablemente fue ésta la razón principal de su muerte y la de su equipo.

Usando el diario de Scott como punto de partida, Bainbridge imaginó otros diarios con las voces de los algunos miembros del grupo, para así dar sus diferentes versiones de la desgraciada aventura. Según la opinión de Murtaugh, la autora ha creado una parábola del valor insensato, como crítica al absurdo optimismo que floreció en la Inglaterra victoriana y murió durante la primera Guerra Mundial.

Sin embargo, como afirma Michiko Kakutani (1994: 143), lo que hace inolvidable el relato de Beryl Bainbridge es la simpatía y candor con que los distintos personajes cuentan sus propias vivencias del viaje, captando el idealismo y el ímpetu juvenil que les impulsó inicialmente a la aventura, y el abatimiento y terror que gradualmente les fue invadiendo durante los últimos días de la misión.

Merece especial mención la verosimilitud en la reproducción de los infortunios que sufren todos los miembros de la expedición, de personalidades tan diferentes, que hace sentir al lector la sensación de compartir con ellos las experiencias directas de ese avance interminable por un paisaje peligroso pero bello.

\section{Master Georgie}

Tras The Birthday Boys y Every Man for Himself, Master Georgie completa su ambiciosa trilogía de relatos históricos, que diseccionan grandes ejemplos de la locura humana. Como explica Elizabeth Gleick (1998: 122), estos tres relatos, de extensión reducida, son epopeyas observadas bajo un microscopio, que reducen la guadaña de la historia a las actuaciones fortuitas de unos cuantos actores humanos.

Beryl Bainbridge llega a todo su esplendor con Master Georgie, el broche de la trilogía de relatos históricos, ofreciendo — según Kate Saunders 
(1998: 59)—el final más adecuado para The Birthday Boys y Every Man For Himself. En realidad, estos tres relatos no tienen un lazo de unión, excepto que retoman acontecimientos cargados de leyenda y los distancian de todas las versiones anteriores conocidas. Es la historia vista de otra forma, como nunca se había visto, ya que Bainbridge derrumba monumentos simplemente destacando todos los pequeños detalles que no encajan en las versiones ya aceptadas.

En esta obra, Beryl Bainbridge vuelve a utilizar su sátira devastadora. Divide la novela en seis secciones, que están basadas en seis fotografías tomadas en un momento crucial de la historia y narradas alternativamente por los tres personajes que comparten la acción junto a Master Georgie - Myrtle, Pompey Jones y Dr Potter-que son arrastrados con él a la Guerra de Crimea.

A Myrtle, la heroína del relato, la familia Hardy la rescata de una cueva de Liverpool y la lleva a su hogar acomodado; probablemente es la hija ilegítima del disoluto Mr. Hardy. Pompey Jones es un golfillo práctico y realista con talento suficiente para sobrevivir. Y Dr. Potter es un geólogo fracasado, con una incapacidad fatal y cómica para ver debajo de la superficie de las cosas.

A Master Georgie - el hijo mayor de los Hardy- lo vemos a través de estos tres pares de ojos, principalmente a través de Myrtle, su esclava. Ella es quien está a sus pies cuando Georgie descubre el cadáver de su padre en la cama de una prostituta. Tanto Pompey como Myrtle le ayudan a evitar el escándalo metiendo el cuerpo en una carreta de cómicos; un estrafalario coche fúnebre, destinado a aparecer de nuevo al final del relato, como símbolo de la indignidad y la brutalidad fortuita de la muerte.

Años más tarde, encontramos a Myrtle transformada de esclava en joven dama, aceptada y querida por toda la familia Hardy. Aparece como la tía solterona, pero las apariencias nunca fueron más engañosas, ya que es la mujer que ha engendrado a los hijos de Georgie al no poder hacerlo su esposa. Durante toda su vida Myrtle ha hecho un ídolo de Georgie, y cuando lo sigue a Scutari como médico que trabaja en las peores condiciones imaginables, es feliz al convertirse en «la dulce compañera de las viejas baladas» (Saunders, 1998: 59), vestida con los uniformes de los muertos para poder seguir a su amado al campo de batalla.

El Dr. Potter vive en una total confusión, reduciendo la historia a detalles personales absurdos: por ejemplo, después de una terrible masacre, lo único que se le ocurre escribir es que así se han solucionado los problemas de transporte: «Over 200 cavalry horses of the Light Brigade stampeded into the camp, their riders having perished in a charge». 
Pompey, cuya fortuna va paralela a la muerte embarazosa del anciano Hardy, conoce el otro lado de Georgie, lo que le mueve hacia una peligrosa aproximación de afecto por los sacrificios que hace Mirtle por él. Está en Crimea como ayudante de fotógrafo (la Guerra de Crimea fue la primera en que se usó la fotografía) y la cámara se presenta aquí como una gran embustera y manipuladora de la historia:

\footnotetext{
Myrtle was outside, dry-eyed, cradling George in her arms. She was crooning to him.

I walked back to the van and found the photographer nearby with his camera set up and five men slouched before him

"What we want», he said, «is a posed group of survivors to show the folks back home». Squinting down the lens he called out, «The balance isn't right. I need another soldier. Fetch one».

I walked back to George. Myrtle had gone and he was lying in the mud. I humped him over my shoulder and carried him to the camera. The men were now standing and I propped him between them. He slumped forward and the soldier to his right supported him round the waist.

«Smile, boys, smile», urged the photographer.

Behind, on the brow of the hill I saw Myrtle, arms stretched wide, circling round and round, like a bird above a robbed nest (p. 190).
}

Esta escena final muestra claramente el desarrollo que ha alcanzado la controvertida dimensión irónica de Bainbridge, pues el reportero ha colocado a Georgie, ya muerto, entre los demás soldados y, por tanto, uno de los personajes que va a aparecer como supervivientes ya ha dejado de existir.

\section{Young Adolf}

A Beryl Bainbride se le ocurrió escribir un relato sobre el joven Hitler cuando estaba leyendo The Life and Death of Adolf Hitler (1973), de Michael Robert Payne, donde se explica que el hermanastro de Hitler, Alois, se había ido a vivir a Liverpool en 1910. Para completar esta información, Bainbridge se trasladó a Nueva York, con el fin de comprobar una entrada en su diario de Bridget Hitler, la esposa de Alois, donde explicaba cómo en 1912 Adolf Hitler, provisto de documentos falsos y huyendo del servicio militar, les visitó en Inglaterra. La autora continuó investigando sobre la vida de Hitler, hasta que al fin comenzó a escribir Young Adolf (1978). Se sentía intrigada por algunas similitudes que iba encontrando entre la personalidad maníaca de su padre (había nacido el mismo año que el dictador) y la de su protagonista, que no es muy atractiva, aunque sí bastante vulnerable y humana. 
Esta obra es una reconstrucción imaginativa de la probable visita que hizo a Liverpool Adolf Hitler, a la edad de veintitrés años, para ver a su hermanastro Alois y a su esposa irlandesa Bridget. Estos miembros de su familia eran pobres, y Adolf es un inconveniente para ellos, ya que es difícil, depresivo y no quiere trabajar, permaneciendo todo el día echado en el sofá. Aunque el joven está sediento de afecto, no hace nada para ganarlo; su comportamiento es violento y paranoico, imaginando que le odian y maltratan a propósito. Cuando una mujer le dice la buenaventura y le compara con Alejandro Magno, cree que se está riendo de él y que todos le desprecian, lo que le hace sentirse aislado, confundido y absurdo. Por fin, cuando consiguen que se marche, jura abandonar para siempre esta «isla de lunáticos», no volviendo nunca a mencionar que había estado en Inglaterra:

"Here and there», said Adolf. He resolved to grow a moustache. Never again would he be mistaken for a woman. Suddenly he wanted to go home more than anything in the world, even though there was no such place. Meyer and Alois between them could pay for his ticket. He could have no compunction in asking them. Alois would be glad to see the back of him and how could Meyer refuse, having whispered Bridget's name in the hall? Never in all my life, thought Adolf, under torture or interrogation, will I mention that I have been to this accursed city, visited this lunatic island (p. 159).

Young Adolf (1978), como afirma Diane Johnson (1978:385), no es un relato histórico en el sentido normal del término - esto es, una dramatización de acontecimientos conocidos- sino una invención artística de la imaginación. Si puede considerarse ficción histórica, es porque utiliza un héroe, tristemente famoso en la Historia próxima europea.

En resumen, como hemos visto, Beryl Bainbridge evoca Historia y personajes, creando efectos surrealistas en su trilogía de relatos históricos: The Birthday Boys (1991) basada en las experiencias del equipo del Capitán Scott en su última y fatal expedición al Polo Sur; Every Man for Himself (1997) una nueva perspectiva de otra tragedia eduardiana, el hundimiento del Titanic que tuvo lugar también en 1912, y Master Georgie (1999) que nos hace retroceder seis décadas a una campaña desastrosa, la carnicería de la Guerra de Crimea. Igualmente utiliza un personaje tristemente histórico en su relato Young Adolf, dando la más sorprendente versión del dictador.

Como afirma Kate Saunders en su ensayo «History as you have never seen it before», Bainbridge cuenta la historia como jamás se había hecho, quedando los héroes reducidos a su dimensión humana. Con su fórmula irónica nos muestra la fragilidad de la vida, el caos y los desastres de la guerra, y la necesidad que tiene la humanidad de crear sus propios ídolos. 


\section{Referencias bibliográficas}

BAINBRIDGE, Beryl 1995 (1979, 1978). Young Adolf. New York: Carroll \& Craft.

- 1995 (1994, 1993, 1991). The Birthday Boys. Bath: Chivers Press.

- (1997). Every Man for Himself. London: Abacus.

- (1999). Master Georgie. Thorndike, Me.: Thorndike Press.

ColLINGwood, R.G. (1946). The ldea of History. Oxford University Press.

Cox, Michel \& Adrian, Jack (1994). The Oxford Book of Historical Stories. Oxford, NY: Oxford University Press.

CRAWFORD, Brad (1999). Writer's Digest 79: 6, 8.

GleICK, Elizabeth (1998). «Mistress of Her Domain: Few Americans knows Britain's

Beryl Bainbridge. Her Master Georgie knows why more about». Time 30, 122.

JoHNSON, Diane (1978). «The Sufferings of Young Hitler». Times Literary Supplement, $1 \mathrm{Dec}, 1385$.

- (1982). «Young Adolf Goes to Beryl Bainbridge's England». En Terrorists and Novelists, 97-114. New York: Knopf.

- (1991). «Fiction as Historical Critique: The Retrospective World War II Novels of Beryl Bainbridge and Maureen Duffy». Fhoebe, Fall, 3: 2, 12-24.

KaKUTANI, Michiko (1994). «The Birthday Boys» (book reviews). The New York Times April 12: 143, 24.

MLlaRD, Barbara C. (1982). «Beryl Bainbridge». Dictionary of Literary Biography 14, 38-49.

Murtaugh, Daniel M. (1998). «Master Georgie». Commonweal 125: 19, 26.

SAUNDERS, Kate (1996) «History as you have never seen it before». New Stateman 127, 4383: 59-60.

SwINDEN, Patrick (1984). The English Novel of History and Society, 1940-80. New York: Sr. Martin's Press.

WILliaMs, John (1996). Fiction as False Document. Columbia, SC: Camden House. WENNÖ, Elisabeth (1993). Ironic Formula in the Novels of Beryl Bainbridge. Göteborg, Sweden: Acta Universitatis Gothoburgenis.

YAKOLVLEVA, Valentina (1984). «On Reading Beryl Bainbridge: A Voice from the Public». Soviet Literature 11, 141-149. 